\author{
J. Kucińska-Lipka*, H. Janik , I. Gubańska \\ Gdansk University of Technology, Chemical Faculty, Polymer Technology Department, \\ 80-233 Gdansk, Poland, *juskucin@pg.gda.pl
}

\title{
NOVEL POLYURETHANES AS ANTIFOULING PAINT MATRICES
}

\begin{abstract}
The new poly(ester-ether urethane)s (PEEUR) were prepared in two stage synthesis from formerly obtained oligo(alkylene ester-ether)diols (OAEE) and 4,4'-diphenylmethane diisocyanate (MDI). PEEUR samples were subjected to crosslinking with styrene in the presence of radical polymerization initiators: methyl ethyl ketone peroxide (MEKPO) or cobalt 2-ethyl cyclohexanoate (EtHCo). Crosslinked PEEUR were characterized by their physicochemical and mechanical properties. Tensile strength of crosslinked PEEURs was in the range 63-29 $\mathrm{MPa}$, hardness values were from 92 to $97^{\circ} \mathrm{ShA}$, and glass transition temperature was in the range $59-74^{\circ} \mathrm{C}$. For PEEURs filled with biocides tensile strength was in the range 6,8-8,5MPa, hardness values were from 82 to $92^{\circ} \mathrm{ShA}$, and glass transition temperature was in the range $57-72^{\circ} \mathrm{C}$. Optical microscopic observations showed that the materials obtained were homogeneous in micrometric scale.
\end{abstract}

Keywords: polyurethane, antifouling protection, unsaturated oligo(alkylene ester-ether)diols, poly(esteretherurethane)s, styrene crosslinking

\section{INTRODUCTION}

In this paper we present the results of study on new polyurethanes, which have been used as antifouling coatings. The reasons for taking up the research in this field was the widespread use of antifouling coating systems, as a security for the underwater part of the hull of ships and for hydraulic structures operated in seawater, against the harmful effects of marine microand macroorganisms (accumulation on the hull surface) of animal and vegetable origin. [1-6] The application of antifouling protection should take into account some very important factors, both economic and environmental. The overgrowth of hull reduces the ship speed and its maneuverability. It also generates a significant increase in fuel consumption. Important from the environment protection point of view is that higher consumption entails increased emissions of COx, NOx and SOx into the atmosphere. So far, many research centres and companies are doing studies on vinyl and silicone antifouling systems. In the market are available products based on these polymers [5-10], but in the literature poly (ester-etherurethane)s as antifouling coatings are not described. 


\section{SUBSTRATES AND SYNTHESIS}

\section{Substrates}

Adipic acid Mw=146,06 (Aldrich); Maleic anhydride $\mathrm{Mw}=98,06$ (Aldrich), poly(oxyethylene) (POE) $\mathrm{Mw}=300$ (Aldrich), propane-1,3-diol $\mathrm{Mw}=76$ (Aldrich), 4,4'-methylenebis(phenyl isocyanate) (MDI) Mw=250 (Borsdochem), styrene(S)-cda $\mathrm{Mw}=104,1$ (Aldrich), solution of cobalt 2-ethyl cyclohexanoate (EtHCo/ILT) (10\% cobalt) in white spirit, 36\% solution of methyl ethyl ketone peroxide (MEKPO) (ILT) in dimethyl phthalate, $0,5 \%$ of organic biocide (zinc pyrithione), $5 \%$ of inorganic biocide (copper monoxide (I)).

\section{Synthesis}

The synthesis of poly(ester-ether urethane) matrix was conducted in three steps. Firstly, the unsaturated oligo(alkyleneester-ether) diols (OAEE) were obtained in polycondensation reaction of adipic acid, maleic anhydride, propane-1,3-diol and poly(oxyethylene) (POE). Secondly, the urethane quasi-prepolymers (QPRE) were obtained from unsaturated OAEE and 4,4'-methylenebis(phenyl diisocyanate). The third step was the synthesis of urethane prepolymers (PRE), which were obtained by chain extension of urethane quasi-prepolymers by formerly synthesized oligo(alkyleneester-ether)diols. Urethane prepolymers were obtained at different ratios of $\mathrm{NCO} / \mathrm{OH}$, in the range of $1,5: 1$ to $3,0: 1$.

\section{ANTYFOULING COATING SYNTHESIS}

Obtained PRE were subjected to crosslinking at room temperature with the use of styrene in amount of $25 \%$ wt towards mass of unsaturated OAEE, performed in the presence of methyl ethyl ketone peroxide (MEKPO) and cobalt 2-ethyl cyclohexanoate (EtHco) or PRE were blended with biocides and then subjected to crosslinking with styrene. This way poly(esterether urethane)s (PEEUR) and poly(estro-ether urethane) (PEEUR) antifouling coatings were obtained.

\section{DISCUSSION}

\section{Properties of obtained unsaturated oligo(alkyleneester-ether)diols}

Obtained oligo(alkyleneester-ether)diols were characterized by acid, hydroxyl and iodine number and also by calculating its molecular weight. The results are presented in the Table (1). 
Table 1. Physicochemical properties of oligo(alkylene ester-ether)diol

\begin{tabular}{|l|l|l|l|l|l|l|}
\hline \multirow{2}{*}{$\begin{array}{l}\text { Sample } \\
\text { symbol }\end{array}$} & $\begin{array}{l}\text { Synthesis } \\
\text { time }\end{array}$ & Acid number & Hydroxyl number & $\begin{array}{l}\text { Molecular } \\
\text { weight }\end{array}$ & \multicolumn{2}{|c|}{ Iodine number } \\
\cline { 2 - 7 } & & & & Theoretic & Determined \\
\hline \multicolumn{7}{|c|}{ Oligo(alkileneester-ether)diols synthesized with propane-1,3-diol and other comonomers } \\
\hline OAEE & 33,5 & 1,1 & 131 & 900 & 22 & 20 \\
\hline
\end{tabular}

The study results presented in Table 1 has showed that obtained unsaturated OAEE have acid number of about $1 \mathrm{mgKOH} / \mathrm{g}$. Hydroxyl number of unsaturated OAEE is in the range of $131 \mathrm{mgKOH} / \mathrm{g}$. Based on hydroxyl number an average molecular weight of studied oligomerol was calculated $(900 \mathrm{~g} / \mathrm{mol})$.

The iodine number of obtained unsaturated oligo(alkylene ester-ether)diol was estimated as $22 \mathrm{gI} / 100 \mathrm{~g}$ and based on this value the number of unsaturated linkages present in the synthesized compound was calculated. Iodine number calculated theoretically was not much higher than that estimated experimentally and that confirm that only small amount of double bonds takes part in chemical reactions of polycondensation process. Decrease of unsaturation level of OAEE, determined that theoretical value was the result of glycol addition to the double bonds coming from maleic anhydride, what in consequence led to chains branching.

\section{Poly(ester-ether urethane)s physicochemical properties}

Table 2 contains experimental data for saturated (25\% wt styrene to the molecular mass of OAEE) poly(ester-eter urethane)s obtained from MDI isocyanate and for unsaturated OAEE containing in their structure residues of propane-1,3-diol and other comonomers.

Table 2. Physicochemical properties of crosslinked poly(ester-ether urethanes) synthesized from MDI isocyanate and of unsaturated OAEE

\begin{tabular}{|l|c|c|c|c|}
\hline Sample symbol & $\begin{array}{c}\text { Tensile strength Tsb } \\
{[\mathrm{MPa}]}\end{array}$ & $\begin{array}{c}\text { Hardness } \\
{\left[{ }^{\circ} \mathrm{Sh} \mathrm{A}\right]}\end{array}$ & $\begin{array}{c}\text { Glass transition } \\
\text { temperature } \\
\mathrm{T}_{\mathrm{g}}\left[{ }^{\circ} \mathrm{C}\right]\end{array}$ & $\begin{array}{c}\text { Mass loss after } 6 \\
\text { months exposition to } \\
\text { sea water [\%] }\end{array}$ \\
\hline PEEUR-1,5/1* & 16 & 92 & 59,4 & 0,2 \\
\hline PEEUR-2,0/1 & 25 & 96 & 66,7 & 0,1 \\
\hline PEEUR-2,5/1 & 23 & 97 & 74,1 & 0 \\
\hline PEEUR-3,0/1 & 29 & 97 & 73,8 & 0 \\
\hline
\end{tabular}

*Poly(ester-ether urethane) symbol: number after dash is ratio of NCO/OH

Poly(ester-ether urethane)s differ in their tensile strength, estimated in the range 16-29 $\mathrm{MPa}$, which depend on $\mathrm{NCO} / \mathrm{OH}$ ratio. The lowest $\mathrm{T}_{\mathrm{SB}}$ value was determined for PEEUR synthesized at $\mathrm{NCO} / \mathrm{OH}$ ratio of $1,5: 1$. PEEUR hardness was in the range of $92^{\circ} \mathrm{ShA}$ (NCO/OH 1,5/1) - 97 ShA (NCO/OH 3,0:1).

As a result of crosslinking copolymerisation between styrene and unsaturated linkages in quasi-prepolymer a high crosslinked structure was formed, what significantly affected the 
tensile strength values of PEEUR samples. Moreover, PEEUR differ in glass transition temperatures (depending on molar ratio of $\mathrm{NCO} / \mathrm{OH}$ changed in the range of 1,5:1 - 3,0:1), measured between $59^{\circ}-74^{\circ} \mathrm{C}$. Based on this differences it can be pointed out that the increase of hard segment content in the PEEUR structure have an impact on glass transition changes (higher $\mathrm{NCO} / \mathrm{OH}$ ratio, from the range of $1,5: 1-3,0: 1$, caused the increase in glass transition temperature of $10-20^{\circ} \mathrm{C}$ )

\section{Physicochemical and mechanical properties of poly(ester-ether polyurethane)s filled with biocides}

Physicochemical and mechanical properties of obtained antifouling coatings were studied by measurements of tensile strength, hardness, glass transition temperature and mass loss of PEEUR containing $0,5 \%$ of organic biocide and 5\% of inorganic biocide after 6 month exposure to the sea water. Analysis of obtained data showed that polyurethanes tensile strength was in the range of $6,8-8,59 \mathrm{MPa}$, hardness values were of $82^{\circ}-92^{\circ} \mathrm{ShA}$ and glass transition temperature was in the range of $57-72^{\circ} \mathrm{C}$ depending on molar ratio of NCO/OH. Obtained coatings were found as resistant to sea water and their mass loss didn't excess $0,4 \%$, independently to the hard segment content. In the Tab (3) data for PEEURs containing biocides are presented

Table 3. Physicochemical and mechanical properties of PEEURs blended with biocides

\begin{tabular}{|l|c|c|c|c|c|}
\hline Sample symbol & $\begin{array}{c}\text { Tensile strength } \\
\text { Tsb[MPa] }\end{array}$ & $\begin{array}{c}\text { Hardness } \\
{\left[{ }^{\circ} \mathrm{Sh} \mathrm{A}\right]}\end{array}$ & $\begin{array}{c}\text { Glass } \\
\text { transition } \\
\text { temperature } \\
\mathrm{T}_{\mathrm{g}}\left[{ }^{\circ} \mathrm{C}\right]\end{array}$ & $\begin{array}{c}\text { Mass loss after 6 } \\
\text { months exposure } \\
\text { to seawater } \\
{[\%]}\end{array}$ & $\begin{array}{c}\text { Tensile strength after 6 } \\
\text { months exposure to } \\
\text { seawater Tsb } \\
{[\mathrm{MPa}]}\end{array}$ \\
\hline PEEUR-1,5/1* & 6,8 & 82 & 57,4 & 0,4 & 6,5 \\
\hline PEEUR-2,0/1 & 6,9 & 86 & 61,3 & 0,3 & 6,7 \\
\hline PEEUR-2,5/1 & 7,3 & 87 & 71,5 & 0,2 & 8,1 \\
\hline PEEUR-3,0/1 & 8,5 & 92 & 72,7 & 0,2 & 8,5 \\
\hline
\end{tabular}

\section{Efficacy evaluation of obtained PEEUR antifouling coatings with the use of optical microscopy}

Poly(ester-ether urethane) coatings and poly(ester-ether urethane) coatings filled with biocides (antifouling cover) after hardening were subjected to the sea water exposure in a 6 months period. Optical microscope analysis of PEEUR materials was carried out before and after sea water exposure. 
a)

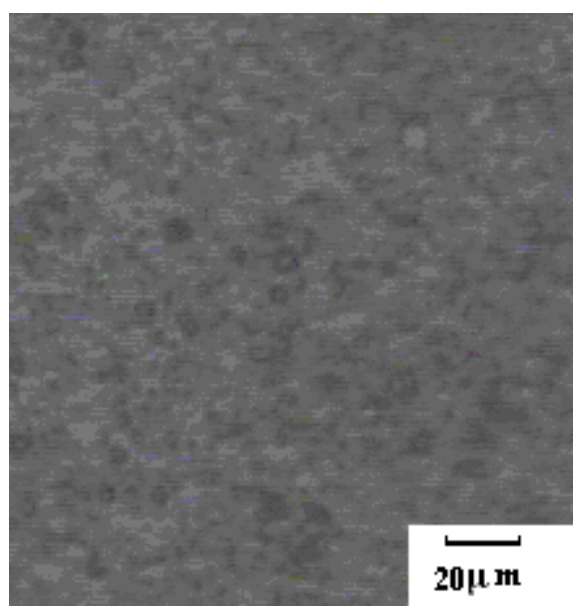

b)

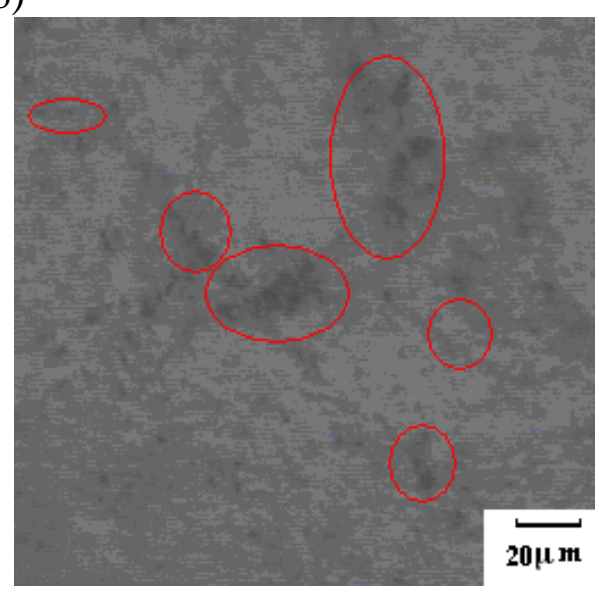

Fig. 1. Optical microscopy examination of PEEUR 3,0:1 coating surface - without biocides; a) coating surface before sea water exposure, b) coating surface after exposure to the sea water

a)

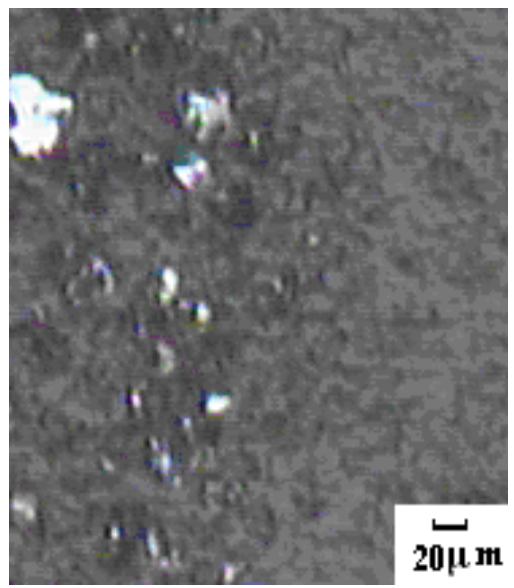

b)

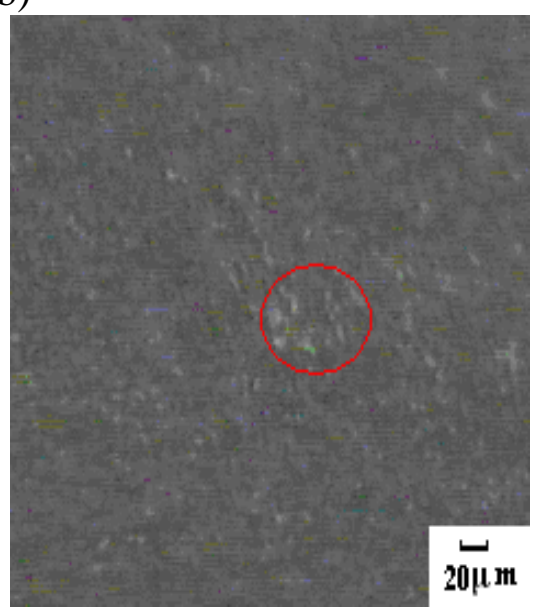

Fig. 2. Optical microscopy examination of PEEUR 3,0:1 coating surface - with biocides a) coating surface before seawater exposure, b) coating surface after exposure to the seawater

Analysis of presented optical microscope images of PEEUR coatings without organic biocide and copper monoxide (I) showed that these coatings do not have antifouling properties. The overgrowth percent of studied surface was in the range of $10-35 \%$. The surface observations of PEEUR filled with biocide showed that formed cover was homogenous, without agglomerates of biocide fillers on its surface. Obtained matrices with biocides were found to be resistant to sea water interactions. Optical microscope evaluation didn't show any microor macrofractures.

\section{CONCLUSIONS}

In this paper was described the synthesis of novel poly(ester-ether urethane)s (PEEUR) for antifouling coatings. PEEUR were obtained from unsaturated oligo(alkyleneester-ether)diols (OAEE) and 4,4'-methylenebis(phenyl isocyanate) (MDI), with or without biocide. Obtained 
polyurethanes were subjected to the crosslinking with styrene. Hardened coatings were examined for their physicochemical and mechanical properties to evaluate their ability for further applications.

Poly(ester-ether urethane) samples, without biocides, have tensile strength, estimated in the range of $16-29 \mathrm{MPa}$, wherein $\mathrm{T}_{\mathrm{SB}}$ parameter depend on $\mathrm{NCO} / \mathrm{OH}$ ratio. Hardness of obtained PEEURs were in the range of $92^{\circ} \mathrm{ShA}-97^{\circ} \mathrm{ShA}$ for sample $\mathrm{NCO} / \mathrm{OH} 1,5 / 1$ and $\mathrm{NCO} / \mathrm{OH}$ $3,0: 1$ respectively. Glass transition temperature was from $59,4^{\circ} \mathrm{C}$ to $73,8^{\circ} \mathrm{C}$. Obtained antifouling PEEUR coatings (containing biocide) have decreased tensile strength $(6,8-8,5$ $\mathrm{MPa})$, but hardness $\left(82-92^{\circ} \mathrm{ShA}\right)$ and glass transition temperature $\left(57,4-72,7^{\circ} \mathrm{C}\right)$ stays in the range of measured values for PEEUR without biocides. Mass loss of PEEUR containing 0,5\% of organic biocide and 5\% of inorganic biocide after 6 month exposure to the sea water is higher than that measured for PEEUR samples without biocides. Optical microscope images of PEEUR coatings without biocide showed that these coatings do not have antifouling properties. The overgrowth percent of studied surface was in the range of $10-35 \%$. The surface observations of PEEUR filled with biocide showed that formed cover was homogenous, without agglomerates of biocide fillers on its surface. Optical microscope evaluation didn't show any micro-or macrofractures. Obtained coatings were found as resistant to sea water and their mass loss didn't excess $0,4 \%$, independently to the hard segment content. PEEUR exposure to the sea water for the 6 month period showed that obtained antifouling coatings do not undergo degradation in seawater and constitute perfect antifouling protection.

Scientific work funded science in the years 2009-2011 as a research project NN 305065937.

\section{REFERENCES}

1. Hellio C., Yerba D. M.: Advances in marine antifouling coatings and technologies, Woodhead Publishing, Cambridge, May 2009.

2. Morrison S.: Antifouling coatings, Surface Coatings Association of New Zealand Inc. 5-10.

3. Turner A.: Marine pollution from antifouling paint particles, Marine Pollution Bulletin 60 (2010), 159-171.

4. Yerba D. M., Kill S., Dam-Johansen K.: Antifouling technology-past, present and future steps towards efficient and environmentally friendly antifouling coatings, PIOC, 50/2004, 75-104.

5. Mirabedini S.M., Pazoki S.,. Esfandeh M, Mohseni M., Akbari Z.: Comparison of drag characteristics of self-polishing co-polymers and silicone foul release coatings: A study of wettability and surface roughness Progress in Organic Coatings 57 (2006), 421-429.

6. Meseguer Yebra D., Kiil S., Kim Dam-Johansen: Progress in Organic Coatings, Volume 50, Issue 2, July 2004, 75-104.

7. Chambers L.D., Stokes K.R., Walsh F.C., Wood R.J.K.: Surface and Coatings Technology, Volume 201, Issue 6, December 2006, 3642-3652.

8. Chapman R.: What's involved in selecting the correct antifouling, PCE 1998.

9. Hellio C. Yebra D.: Advances in marine antifouling coatings and technologies. Washington 2009.

10. Schiff K., Diehl D., Valkirs A.: Marine Pollution Bulletin, Volume 48, Issues 3-4, February 2004, 371-37. 